\title{
Depression and quality of life in patients on long term hemodialysis at a national hospital in Ghana: a cross-sectional study
}

\author{
Vincent J. Ganu ${ }^{1}$, Vincent Boima ${ }^{2}$, David N. Adjei ${ }^{3}$, Joana S. Yendork ${ }^{5}$, Ida D. Dey ${ }^{2}$, Ernest Yorke ${ }^{2}$, \\ Charles C. Mate-Kole ${ }^{4,5,6}$ and Michael O. Mate-Kole ${ }^{2}$
}

Ghana Med J 2018; 52(6): 22-28 DOI: http://dx.doi.org/10.4314/gmj.v52i1.5

\begin{abstract}
${ }^{1}$ Department of Medicine and Therapeutics, Korle-Bu Teaching Hospital, Accra ${ }^{2}$ Department of Medicine and Therapeutics, School of Medicine and Dentistry, College of Health Sciences, University of Ghana, Accra ${ }^{3}$ School of Biomedical and Allied Health Sciences, College of Health Sciences, University of Ghana, Box 4236, Accra ${ }^{4}$ Department of Psychiatry, School of Medicine and Dentistry, College of Health Sciences, University of Ghana, Box 4236, Accra ${ }^{5}$ Department of Psychology, University of Ghana, Legon ${ }^{6}$ Centre for Ageing Studies, University of Ghana, Legon
\end{abstract}

Corresponding author: Vincent J Ganu

E-mail: vincentjganu@gmail.com

Conflict of interest: None declared

\section{SUMMARY}

The study examined quality of life and prevalence of depressive symptoms in patients on long term hemodialysis. Further, it explored the impact of socio-demographic characteristics on depression and quality of life.

Design: Study design was cross-sectional.

Setting: Study was conducted in the two renal dialysis units of the Korle-Bu Teaching hospital in Accra, Ghana.

Participants and study tools: One hundred and six participants on haemodialysis were recruited for the study. The Patient Health Questionnaire and the World Health Organization Quality of Life instrument were used to assess depression and quality of life.

Results Forty five percent of participants screened positive for symptoms of depression. Approximately 19\% obtained low scores on overall quality of life. There were significant negative correlations between the following: Depression and overall QoL, Depression and duration of dialysis treatment and Depression and income level. There was positive correlation between overall $\mathrm{QoL}$ and duration of dialysis, treatment and income.

Conclusion: Depressive symptoms were common amongst patients on long term hemodialysis. Haemodialysis patients who obtained low scores on quality of life measures were more likely to screen positive for depressive symptoms. Screening for depressive symptoms among these patients is critical as early treatment may improve their general wellbeing.

Funding: Not indicayed

Keywords: Depression, quality of life, hemodialysis, chronic kidney disease

\section{INTRODUCTION}

Studies on End Stage Renal Disease (ESRD) have reported an increase in the burden of the disease worldwide due to increasing prevalence of diabetes and hypertension. ${ }^{1,2}$ Studies have reported an increase in ESRD cases by approximately $70 \%$ in the past 20 years. ${ }^{3}$ ESRD is accompanied by increased mortality and escalating costs of providing care for patients. ${ }^{4,5}$ Despite the advances in the treatment of ESRD, affected individuals still report low quality of life. ${ }^{6}$ ESRD results in a decline in physical functioning, poor psychological health and medical complications such as anemia and neurological disorders. ${ }^{7}$
In addition, complications of hemodialysis (i.e., hypotension, headache and air embolism) may contribute to diminished working capacity and adversely affect individual productivity. ${ }^{7}$ Factors such as financial dependence, inability to carry out family responsibilities, and engage in active social life, have been attributed to reduced quality of life in patients on long-term hemodialysis. These factors may result in mental health issues such as depression, anxiety and impaired cognition. ${ }^{8}$ 
Depression is reported to be one of the most common psychological conditions among ESRD patients on hemodialysis. ${ }^{9}$ A study in a tertiary hospital among hemodialysis patients in Nigeria found the prevalence of depression to be $34.5 \%{ }^{10}$ compared to a prevalence of $27 \%$ among African American hemodialysis patients. ${ }^{11}$ Another study conducted on depression among ESRD patients in Sudan reported a prevalence of $72 \% .{ }^{12}$

The risk factors for depression among ESRD patients include low compliance to medications, poor nutritional status and marital problems. ${ }^{13}$ Depression may be linked to significant restrictions in independent living due to the hemodialysis treatment modality. Patients on dialysis are connected to the hemodialysis machine for at least 2 hours per session with a minimum of three sessions per week. ${ }^{14}$

Socio-demographic variables such as age and family support have been reported to play a significant role in the psychological wellbeing of haemodialysis patients. ${ }^{15} \mathrm{~Pa}$ tients with varying times on dialysis have also reported differences in their accounts of perceived consequences of treatment (i.e., depression). ${ }^{16}$

The burden of ESRD is rising and presents a challenge for both developed and emerging economies. Psychological problems among these patients have been largely understudied in Africa, and to our knowledge, there is no data on this subject in Ghana. The present study examined the prevalence of depression and quality of life status among patients with ESRD on hemodialysis. Further, it explored the impact of demographic characteristics on depression and quality of life.

\section{METHODS}

The study design was cross-sectional and was conducted at the two renal dialysis units (Department of Medicine and Cardiothoracic Center) of the Korle-Bu Teaching hospital in Accra, Ghana. These renal dialysis units serve as referral centres and offer only haemodialysis for all kidney disease patients. Recruitment of the participants was based on these criteria: 1) Clinical diagnosis of endstage renal disease; 2) Hemodialysis treatment; 3) Age 18 years and above; 4) Voluntary participation and signed consent form.

Participants were briefed on the nature of the study and made aware that they could decide at any point in time to discontinue without any negative consequences. Participants who gave consent were included in the study and they completed the self-administered questionnaires.
Self-administered questionnaires used included the World Health Organization Quality of Life (WHOQOL BREF) ${ }^{17}$ and the Patient Health Questionnaire (PHQ-9) comprising 9 items. $^{18}$

The PHQ-9 is one of the most commonly used tests for screening depression in many settings. ${ }^{19}$ It consists of 9items that measure the incidence of depressive thoughts and feelings in individuals over the previous two weeks. The PHQ-9 is a 4-point Likert scale with a range from 0 to 3. Zero for "not at all" responses and 3 for "nearly every day" responses. Scores range from 0 to 27 . The interpretation of the scores were done along these dimensions: a score less than 10 demonstrated no symptoms of depression; scores from 10 to 14 demonstrated symptoms of moderate depression; scores 15 to 19 depicted symptoms of moderately severe depression, and scores from 20 to 27 depicted symptoms of severe depression. The Cronbach's alpha of the PHQ-9 for the present sample was 0.815 .

The WHOQOL-BREF, a shorter form of the WHOQOL100 was administered. It assessed four domains of QoL; namely, physical, psychological, social and environmental. Items on this measure were scored on a 5-point Likert scale. The scores range from 1 (low) to 5 (high) with increasing scores from 1 to 5 denoting higher QoL. The raw domain scores obtained from the WHOQOL-BREF were transformed to a 4-20 score and then scaled in a positive direction (i.e. higher scores denoting higher quality of life). The mean score within each domain is used to calculate the domain score and these are linearly transformed to a $0-100$ scale. $^{20}$ The Cronbach's alpha of the WHOQOL-BREF for the present sample was 0.815 .

\section{Statistical analysis}

SPSS statistical software version 20.0 was used for data cleaning and analysis. Categorical variables were analyzed and presented as frequencies and percentages. The continuous variables were presented as means and standard deviations. Preliminary analyses were conducted to ascertain the normality of the data. The results showed that all the variables (depression, the total and domain scores of QoL) had skewness and kurtosis values that fell within +2 and -2 , thus, indicating that the data was close to normal in line with the criteria proposed by George and Mallery. ${ }^{21}$ Inferential statistics were carried out using the independent sample t-test to compare participants with differences in demographic characteristics on scores of depression, overall QoL and the four domains of QoL. Bonferroni adjustment was used to adjust the alpha level for the results of the t-test to 0.008 in order to control for Type I error due to multiple analyses. In addition, the Pearson Correlation Coefficient was used to compute the relationship between symptoms of depression, quality of 
life, dialysis treatment duration and income.Standard linear multiple regression was used to explore selected variables that would predict overall quality of life. Significance level for all other analysis was set at a p-value less than 0.05 .

\section{Ethics statement}

This study was approved by the Ethical and Protocol Review Committee of the College of Health Sciences, University of Ghana with protocol identification number MS-Et/M.5 - P 3.2/2012-2013.

\section{RESULTS}

At the time of the study, there were 129 ESRD patients on dialysis at the Korle-Bu Teaching Hospital. Of the 129 ESRD patients, 106, aged between 21-79 years (mean = 48.7; $\mathrm{SD}=1.33$ ). consented and participated in the study, giving a response rate of $82 \%$. Table 1 shows the demographic characteristics of the participants.

As illustrated in Table 2, the prevalence of depressive symptoms among the participants was approximately $44 \%$ with about $6 \%$ screening positive for severe depression. Eighty-six $(81 \%)$ of the respondents obtained high scores on the WHO-QOL BREF while 20 (19\%) had low scores. In terms of the domains of quality of life, 104 participants (98\%) scored low on social relationship wellbeing while $18(17 \%)$ had poor psychological wellbeing.

\section{Comparisons of Depression and QoL scores for the various demographic variables}

The independent t-test was computed to examine between-group differences on education (high vs low), income (high vs low) and participants' scores on depression, overall QoL and the four domains of QoL.

Table 1 Distributions of demographic characteristics of participants. $(\mathrm{N}=106)$

\begin{tabular}{llll} 
Variable & & Frequency & Percent \\
\hline Age & $20-29$ & 10 & 9.4 \\
& $30-39$ & 16 & 15.1 \\
& $40-49$ & 29 & 27.4 \\
& $50-59$ & 24 & 22.6 \\
& $60-69$ & 21 & 19.8 \\
Sex & $70 \geq$ & 6 & 5.7 \\
\multirow{3}{*}{ Marital Status } & Male & 63 & 59.4 \\
& Female & 43 & 40.6 \\
& Married & 15 & 14.15 \\
& Divorced & 81 & 76.41 \\
& Widow/Widower & 6 & 3.78 \\
& & & 5.66
\end{tabular}

\begin{tabular}{|c|c|c|c|}
\hline Variable & & Frequency & Percent \\
\hline \multirow[t]{4}{*}{$\begin{array}{l}\text { Educational } \\
\text { Status }\end{array}$} & Primary & 2 & 1.9 \\
\hline & Junior High School & 14 & 13.2 \\
\hline & Senior High School & 35 & 33 \\
\hline & Tertiary Education & 55 & 51.9 \\
\hline \multirow[t]{4}{*}{$\begin{array}{l}\text { Employment } \\
\text { status }\end{array}$} & Actively working & 39 & 36.8 \\
\hline & Not actively working & 48 & 45.3 \\
\hline & Pensioners & 12 & 11.3 \\
\hline & Student & 7 & 6.6 \\
\hline \multirow[t]{3}{*}{$\begin{array}{l}\text { Transporta- } \\
\text { tion }\end{array}$} & Private/Own car & 37 & 34.9 \\
\hline & Public: Taxi & 56 & 52.8 \\
\hline & Public: Other & 13 & 12.3 \\
\hline \multirow[t]{2}{*}{ Disability } & Yes & 7 & 6.6 \\
\hline & No & 99 & 93.4 \\
\hline
\end{tabular}

Table 2 Distribution of depression and quality of life among End Stage Renal Disease patients on haemodialysis at a tertiary hospital in Ghana, 2013.

\begin{tabular}{|c|c|c|c|c|c|}
\hline Variabl & & $\begin{array}{l}\text { Fre- } \\
\text { quency }\end{array}$ & $\begin{array}{l}\text { Per- } \\
\text { cent }\end{array}$ & & \\
\hline \multicolumn{6}{|c|}{ Depression } \\
\hline \multirow{14}{*}{$\begin{array}{l}\text { Quality } \\
\text { Life }\end{array}$} & \multirow{4}{*}{$\begin{array}{l}\text { Normal } \\
\text { Moderate De- } \\
\text { pression } \\
\text { Moderately Se- } \\
\text { vere Depression } \\
\text { Severe Depres- } \\
\text { sion }\end{array}$} & 59 & 55.66 & & \\
\hline & & 28 & 26.42 & & \\
\hline & & 13 & 12.26 & & \\
\hline & & 6 & 5.66 & & \\
\hline & \multirow[t]{3}{*}{ Total } & 106 & 100 & & \\
\hline & & \multirow{2}{*}{$\begin{array}{l}\text { Very } \\
\text { good } \\
\mathrm{n}(\%)\end{array}$} & Good & Poor & Total \\
\hline & & & $\mathrm{n}(\%)$ & $\mathrm{n}(\%)$ & $\mathrm{n}(\%)$ \\
\hline & \multirow[t]{2}{*}{ Overall } & \multirow[t]{2}{*}{$10(9.4)$} & $\begin{array}{l}76 \\
(71.7)\end{array}$ & $\begin{array}{l}20 \\
(18.9)\end{array}$ & $\begin{array}{l}106 \\
(100)\end{array}$ \\
\hline & & & $\begin{array}{l}44 \\
(41.5)\end{array}$ & $\begin{array}{l}4 \\
(3.8)\end{array}$ & $\begin{array}{l}106 \\
(100)\end{array}$ \\
\hline & Physical & $58(54.7)$ & & 18 & 106 \\
\hline & \multirow{4}{*}{$\begin{array}{l}\text { Psychosocial } \\
\text { Social relation- } \\
\text { ship }\end{array}$} & $15(14.2)$ & (68.8) & (17.0) & (100) \\
\hline & & & & 104 & 106 \\
\hline & & $1(0.9)$ & $(0.9)$ & $(98.2)$ & (100) \\
\hline & & $81(77.1)$ & $\begin{array}{l}21 \\
(20.0)\end{array}$ & $\begin{array}{l}3 \\
(2.9)\end{array}$ & $\begin{array}{l}105 \\
(100)\end{array}$ \\
\hline
\end{tabular}

As shown in Table 3, participants with higher levels of education reported higher scores on overall QoL and the four domains of QoL than those with low levels of education. With regards to transportation, significant differences emerged on all the variables. Those who used private transportation reported less depressive symptoms than those who used public transportation (See Table 3). 


\section{Original Article}

Table 3 T-test results for the differences between ESRD patients on haemodialysis on selected demographic characteristics.

\begin{tabular}{|c|c|c|c|c|c|c|c|c|c|}
\hline Measure & $\begin{array}{c}\quad \text { Ed } \\
\text { No ter- } \\
\text { tiary } \\
\text { Mean } \\
(\mathrm{SD}) \\
\end{array}$ & $\begin{array}{c}\text { Tertiary } \\
\text { Mean } \\
\text { (SD) }\end{array}$ & $95 \% \mathrm{CI}$ & $\begin{array}{l}\text { Trans- } \\
\text { portation }\end{array}$ & $\begin{array}{c}\text { Private } \\
\text { Mean } \\
\text { (SD) }\end{array}$ & $95 \% \mathrm{CI}$ & $\begin{array}{c}\text { Employment } \\
\text { Unem- } \\
\text { ployed } \\
\text { Mean } \\
(\mathrm{SD}) \\
\end{array}$ & $\begin{array}{c}\text { Em- } \\
\text { ployed } \\
\text { Mean } \\
(\mathrm{SD})\end{array}$ & $95 \% \mathrm{CI}$ \\
\hline \multirow{3}{*}{ Overall QoL } & 69.86 & 82.6 & & 71.07 & 86.54 & $-21.61--$ & 71.84 & 84.44 & \multirow{3}{*}{$-18.38--6.82$} \\
\hline & $(12.57)$ & (15.81) & $0.15-0.54$ & $(12.82)$ & $(15.6)$ & 9.87 & $(12.68)$ & (17.14) & \\
\hline & 40.74 & 53.38 & $-19.33--$ & 42.14 & 56.92 & $-21.67--$ & 41.95 & 56.49 & \\
\hline Qol-Physical & $(15.69)$ & (18.77) & 5.95 & (16.74) & (17.68) & 7.88 & $(15.21)$ & (19.93) & \multirow[t]{2}{*}{$-21.36--7.71$} \\
\hline QoL-Psycho- & 42.61 & 56.51 & $-20.6--$ & 45.23 & 58.89 & & 45.01 & 58.67 & \\
\hline logical & $(14.52)$ & (17.78) & 8.04 & $(14.71)$ & (19.64) & $-20.3--6.9$ & $(14.17)$ & (19.99) & \multirow[t]{2}{*}{$-20.26--7.05$} \\
\hline & 28.37 & 38.51 & -18.12- - & 30.05 & 40.32 & -18.67- - & 29.55 & 40.64 & \\
\hline QoL-Social & (17.84) & $(23.07)$ & 2.15 & (18.94) & (23.83) & 1.89 & $(20.84)$ & $(20.32)$ & $-19.34--2.84$ \\
\hline QoL-Environ- & 48.57 & 59.76 & $-16.67--$ & 48.45 & 65.43 & $-22.24--$ & 51.82 & 58.77 & \\
\hline ment & (14.04) & (14.49) & 5.69 & $(12.7)$ & $(13.55)$ & 11.73 & $(13.03)$ & $(17.86)$ & $-12.93--0.41$ \\
\hline
\end{tabular}

On employment (actively working), significant differences were noted on these variables; Overall QoL ( $t[104]$ $=-4.32,95 \% \mathrm{CI}=-18.38--6.82)$, Physical health $(t[104]$ $=-4.22,95 \% \mathrm{CI}=-21.36--7.71)$, Psychological health $(t[104]=-4.1,95 \% \mathrm{CI}=-20.26--7.05)$, Social Relationship $(t[104]=-2.67,95 \% \mathrm{CI}=-19.34--2.84)$ and Environment $(t[104]=-2.3,95 \% \mathrm{CI}=-12.93--0.41)$. Those who were actively working reported less depressive symptoms than those who were not actively working.
Actively working participants reported higher overall QoL than those not actively working. Actively working participants reported better physical health than those not actively working. Actively working participants reported better psychological health than those not actively working. Actively working participants reported better social relationships than those not actively working. Lastly, those who were actively working reported better environmental wellbeing than those not actively working.

Table 4 Summary of inter-correlations for scores on WHOQOL_BREF, PHQ, Income and Treatment Duration in ESRD patients on haemodialysis a tertiary hospital in Ghana, 2013

\begin{tabular}{|c|c|c|c|c|c|c|c|c|}
\hline Measures & 1 & 2 & 3 & 4 & 5 & 6 & 7 & 8 \\
\hline 1. WHOQOL-BREF Total & 1 & & & & & & & \\
\hline 2. Physical Health & $.812 * *$ & 1 & & & & & & \\
\hline 4. Social Relationships & $.722 * *$ & $.521 * *$ & $.628 * *$ & 1 & & & & \\
\hline 5. Environment & $.806^{* *}$ & $.729 * *$ & $.747 * *$ & $.515^{* *}$ & 1 & & & \\
\hline 7. Treatment duration & $.303 * *$ & $.317 * *$ & $.361 * *$ & $.296^{* *}$ & $.28 * *$ & $-.339 * *$ & 1 & \\
\hline 8. Income & $.191 *$ & .186 & $.251 * *$ & .043 & $.224 *$ & -.155 & .162 & 1 \\
\hline
\end{tabular}

Note. ${ }^{*} p<.05 ; * * p<.01$

WHOQOL-BREF - World Health Organization Quality of Life

$P H Q$ - Patient Health Questionnaire

Treatment duration is in months

Income is in Ghana Cedis

Relationship between QoL, Depression, Treatment duration and Income

The Pearson's correlation analyses were conducted to explore relationships among the variables. The results, as shown in Table 4 revealed a negative correlation between depression and overall QoL $(\mathrm{r}=-0.54, \mathrm{p}=.0001)$, physical health $(\mathrm{r}=-0.62, \mathrm{p}=0.0001)$, psychological health $(r=-0.52, p=0.0001)$, social relationship $(r=-0.32, p=$
$0.0001)$, environment $(r=-0.54, p=0.0001)$, and treatment duration $(\mathrm{r}=-0.34, \mathrm{p}=0.0001)$.

There were, also, positive correlations between treatment duration and the following: overall QoL $(r=0.30 ; p=$ $0.002)$, physical wellbeing $(r=0.32 ; \mathrm{p}=0.001)$, psychosocial $(\mathrm{r}=0.36 ; \mathrm{p}=0.0001)$, social relationships $(\mathrm{r}=$ $0.30 ; p=0.005)$ and environmental wellbeing $(r=0.28$; $\mathrm{p}=0.004)$. 
Additionally, income correlated positively with overall QoL $(\mathrm{r}=0.19, \mathrm{p}=0.05)$, physical health $(\mathrm{r}=0.19, \mathrm{p}=$ $0.05)$ and environmental well-being $(r=0.22, p=0.021)$.

\section{Selected predictors of overall QoL}

Standard linear regression analyses were performed to examine whether depression, income (assessed in Ghana Cedis) and treatment duration (in number of months on dialysis) predicted overall quality of life. Table 5 shows that depressive symptoms $(\beta=-0.483,95 \% \mathrm{CI}=-0.998$ - -0.47) emerged as a significant predictor of overall QoL, but not income $(\beta=-0.10,95 \% \mathrm{CI}=0.000-0.001)$ and dialysis treatment duration $(\beta=-0.12,95 \% \mathrm{CI}=$ $0.231-1.375)$.

Table 5 Standard linear regression analysis for selected predictors of quality of life in ESRD patients at a tertiary hospital in Ghana, 2013.

\begin{tabular}{lll}
\hline Variables & $B$ & $95 \%$ CI \\
\hline Depression & -0.483 & $-.998--.47$ \\
Income (Ghana Cedis) & 0.096 & $.000-.001$ \\
Treatment duration (months) & 0.124 & $-.231-1.375$ \\
\hline
\end{tabular}

\section{DISCUSSION}

This study revealed that depressive symptoms were high (prevalence of 44\%) among ESRD patients. In addition, about $20 \%$ of these patients reported poor quality of life. Overall, there were significant relationships between respondent's overall QoL and depression, educational level of respondents, employment status, levels of income and means of transportation. The presence of depressive symptoms was negatively correlated with overall QoL and treatment duration.

The prevalence of depressive symptoms amongst our patients was lower than the prevalence of $72 \%$ reported in similar study in Sudan. ${ }^{12}$ However, prevalence of depressive symptoms was higher in our study compared to a prevalence of $20.1 \%$ reported in another study from the United States of America. ${ }^{22}$ The prevalence of depressive symptoms found among hemodialysis patients in the present study could have resulted from the influence of factors such as loss of jobs, low levels of income.

The drastic changes of one's lifestyle as a result of spending about 3 hours per day on dialysis machine is a contributory factor to the high prevalence rate of depression. Previous studies reported substantial variation in the incidence rate of moderate to severe depression ranging from $33.3 \%$ to $78.8 \%$ among ESRD patients on haemodialysis treatment. 23,24
This might be due to socio-cultural and economic differences amongst study populations in addition to the use of different tools in assessing depression.

Majority of our patients (91.5\%) had supportive family members and most patients had received at least, nine years of education ( $84.9 \%)$. These factors might have enhanced their coping skills about long standing debilitating illness and the subsequent treatment. A similar finding has been reported in a study among African American patients on dialysis in the United States..$^{25}$ The significant number of participants with good family support may stem from the fact that majority of them $(76.4 \%)$ were married. Being married is linked to better physical and emotional well-being and might not be associated with depression. ${ }^{26}$ However, our study did not support previous studies. ${ }^{26}$ Almost $50 \%$ of our dialysis population $(45.3 \%)$ were not actively working. The findings are similar to outcomes from other studies in which unemployment rate amongst patients was $66 \% .{ }^{27}$

Our study revealed that income correlated positively with overall QoL, physical health and environmental well-being, but negatively correlated with depression. This is not surprising since most of our patients had limited funds for dialysis treatment and they could only afford a session or two of hemodialysis treatment per week. Similarly, other studies have shown significant association between depression and level of income. ${ }^{28}$

Eighteen percent of the participants in the present study reported poor quality of life. The changes in patients' social relationship and psychological wellbeing due to illness symptoms have been recognized as factors contributing to the poor quality of life. Our explanation supports reports from other studies which suggested that patients on haemodialysis suffer psychological problems in addition to the physical challenges. ${ }^{29}$ Having higher scores for depression were associated with poorer QoL. The present findings also support the association between depression and poor QoL. ${ }^{24,30}$

Our study revealed that there is a significant relationship between income and QoL; this is supported by previous studies. ${ }^{31}$ Similarly, low socio-economic status of these patients have been reported by some studies to significantly affect patients' QoL..$^{23,29}$

The awareness of one's chronic disease which helps in coping with the disease has reportedly been affected positively by a higher level of education. ${ }^{32}$ Our findings of a significant association between level of education and the physical wellbeing, psychosocial wellbeing and environmental wellbeing domains are similar to other studies. ${ }^{33}$ 
Further, we noted a significant relationship between employment and QoL and our findings further support findings from other studies. ${ }^{33,34}$ Employment is reported to improve QoL of ESRD patients probably due to the regular income which caters for the costs of treatment. ${ }^{33,34}$

There are limitations in the present study. Some of the patients were interviewed during dialysis; therefore, immediate effects of dialysis on symptom reporting such as hypotension cannot be ruled out. Second, the use of a cross-sectional design limited the assessment of the development of symptoms across the continuum of chronic kidney disease stages. Therefore, we could not assess the associations of ESRD symptoms, depression and impaired quality of life with severe adverse patients' outcomes. Third, our study did not include a qualitative design which would have delineated some of the pertinent issues.

Nevertheless, our study has highlighted significant findings of depression, poor QoL and associated factors with poor QoL. A more integrated and holistic approach to treatment which would embrace psychologists, nurses, clinicians and other health professionals should be considered. Intervention programmes should be instituted and should include components that identify and treat depression, in addition to adjusting physiological factors to improve the QoL in ESRD patients on hemodialysis. Additionally, our study emphasizes the need for social workers and clinical psychologists in renal care. Their roles would include addressing patients' emotional needs; enhancement of their coping skills; helping patients with insurance support; adjustment to treatment plans and dietary changes.

This collaborative work with the clinical psychology unit has helped to foster a congenial working relationship. As a result, psychologists now work closely with renal team and regularly attend to the psychological needs of our patients.

Findings from this study should be used to inform healthcare providers responsible for ESRD patients on hemodialysis regarding ways to improve their psychological wellbeing in Ghana. However, future studies on the qualitative aspect of this study would be conducted using focus group discussions and interviews with health service providers and patients. This would highlight the exceptional features of dialysis care on the African continent.

Anecdotal evidence from our study indicate that cultural issues such as religiosity and spirituality have been observed to be good predictors of coping in our part of the world. We recommend that future studies should consider these factors.

\section{ACKNOWLEDGEMENT}

We thank the staff and patients of the of the dialysis units of the Cardiothoracic and Renal units of the Korle-Bu Teaching Hospital for their invaluable contribution to this study.

\section{REFERENCES}

1. White SL, Chadban SJ, Jan S, Chapman JR, Cass A. How can we achieve global equity in provision of renal replacement therapy? Bull World Health Organ. 2008;86(3):229-237.

2. Van Buren PN, Toto R. Hypertension in Diabetic Nephropathy: Epidemiology, Mechanisms, and Management. Adv Chronic Kidney Dis. 2011;18(1):28-41.

3. Thomas B, Wulf S, Bikbov B, et al. Maintenance Dialysis throughout the World in Years 1990 and 2010. J Am Soc Nephrol. 2015;26(11):2621-2633.

4. Anutrakulchai S, Mairiang P, Pongskul C, et al. Mortality and treatment costs of hospitalized chronic kidney disease patients between the three major health insurance schemes in Thailand. $B M C$ Health Serv Res. 2016;16(1):528.

5. Makusidi MA, Liman HM, Yakubu A, Isah MD, Abdullahi S, Chijioke A. Hemodialysis performance and outcomes among end stage renal disease patients from Sokoto, North-Western Nigeria. Indian J Nephrol. 2014;24(2):82-85.

6. Sathvik BS, Parthasarathi G, Narahari MG, Gurudev KC. An assessment of the quality of life in hemodialysis patients using the WHOQOLBREF questionnaire. Indian $J$ Nephrol. 2008;18(4):141-149.

7. O'Callaghan CA. The Renal System at a Glance. third. Chichester, West Sussex, PO19 8SQ, UK: John Wiley \& Sons Ltd,; 2009.

8. Sarnak MJ, Tighiouart H, Scott TM, et al. Frequency of and risk factors for poor cognitive performance in hemodialysis patients. Neurology. 2013;80(5):471-480.

9. Teles F, Azevedo VFD de, Miranda CT de, Miranda MP de M, Teixeira M do C, Elias RM. Depression in hemodialysis patients: the role of dialysis shift. Clin (São Paulo, Brazil). 2014;69(3):198-202.

10. Amira O. Prevalence of symptoms of depression among patients with chronic kidney disease. Niger $J$ Clin Pract. 2011;14(4):460.

11. Weisbord SD, Fried LF, Unruh ML, et al. Associations of race with depression and symptoms in patients on maintenance haemodialysis. Nephrol Dial Transplant. 2007;22(1):203-208.

12. Kaballo BG, Idris M, Alhaj HI, Gaddour M. Psychological Disorders and Quality of Life among 
Sudanese Dialysis Patients and Renal Transplant Recipients. Sudan J Med Sci. 2010;5(4):29-34.

13. Kimmel, Paul L.,Peterson, Rolf A. Psychosocial Factors In Patients With Chronic Kidney Disease: Depression in End-Stage Renal Disease Patients Treated With Hemodialysis: Tools, Correlates, Outcomes, and Needs. Semin Dial. 2008;18(2):9197.

14. Karamanidou C, Theofilou P, Ginieri-Coccossis M, Synodinou C, Papadimitriou G. P01-263 Anxiety, depression and health beliefs in end stage renal disease (ESRD) patients. Eur Psychiatry. 2009;24:S651.

15. Turkistani I, Nuqali A, Badawi M, et al. The prevalence of anxiety and depression among end-stage renal disease patients on hemodialysis in Saudi Arabia. Ren Fail. 2014;36(10):1510-1515.

16. Jansen DL, Heijmans MJWM, Rijken M, et al. Illness perceptions and treatment perceptions of patients with chronic kidney disease: different phases, different perceptions? Br J Health Psychol. 2013;18(2):244-262.

17. Skevington SM, Lotfy M, O'Connell KA. The World Health Organization's WHOQOL-BREF quality of life assessment: Psychometric properties and results of the international field trial. A Report from the WHOQOL Group. Qual Life Res. 2004;13(2):299-310.

18. Spitzer RL, Kroenke K, Williams JB. Validation and utility of a self-report version of PRIME-MD: the PHQ primary care study. Primary Care Evaluation of Mental Disorders. Patient Health Questionnaire. JAMA. 1999;282(18):1737-1744.

19. Nease DE, Maloin JM. Depression screening: a practical strategy. J Fam Pract. 2003;52(2):118124.

20. Skevington SM, Tucker C. Designing response scales for cross-cultural use in health care: data from the development of the UK WHOQOL. $B r J$ Med Psychol. 1999;72 ( Pt 1):51-61.

21. George, D. and Mallery P. SPSS for Windows. Boston MA: Allyn and Bacon; 2001.

22. Shim RS, Baltrus P, Ye J, Rust G. Prevalence, treatment, and control of depressive symptoms in the United States: results from the National Health and Nutrition Examination Survey (NHANES), 2005-2008. J Am Board Fam Med. 2011;24:3338.

23. Cukor D, Cohen SD, Peterson RA, Kimmel PL. Psychosocial aspects of chronic disease: ESRD as a paradigmatic illness. $J$ Am Soc Nephrol. 2007;18(12):3042-3055.

24. Ismail S SO. Evaluation of depression, quality oflife and malnutrition-inflammation scores in hemodialysis patient: Nephrol Dial Transplant Plus. 2008;1(1):59-60.

25. Spinale J, Cohen SD, Khetpal P, et al. Spirituality, Social Support, and Survival in Hemodialysis Patients. Clin J Am Soc Nephrol. 2008;3(6):16201627.

26. Bohlke M, Nunes DL, Marini SS, Kitamura C, Andrade M, Von-Gysel MPO. Predictors of quality of life among patients on dialysis in southern Brazil. Sao Paulo Med J. 2008;126(5):252-256.

27. Patzer RE, Plantinga L, Krisher J, Pastan SO. Dialysis Facility and Network Factors Associated With Low Kidney Transplantation Rates Among United States Dialysis Facilities. Am J Transplant. 2014;14(7):1562-1572.

28. AlDukhayel A. Prevalence of Depressive Symptoms among Hemodialysis and Peritoneal Dialysis Patients. Int J Health Sci (Qassim). 2015;9(1):916.

29. Bayoumi M, Alwakeel J. Hemodialysis Patients Needs Priorities According to Maslows' Hierarchy and Quality of Life. $J$ Palliat Care Med. 2013;2(2).

30. Cruz LN, Fleck MP de A, Polanczyk CA. Depression as a determinant of quality of life in patients with chronic disease: data from Brazil. Soc Psychiatry Psychiatr Epidemiol. 2010;45(10):953961.

31. Ikonomou M, Skapinakis $\mathrm{P}$, Balafa O, Eleftheroudi M, Damigos D, Siamopoulos KC. The impact of socioeconomic factors on quality of life of patients with chronic kidney disease in greece. J Ren Care. 2015;41(4):239-246.

32. Patti F, Pozzilli C, Montanari E, et al. Effects of education level and employment status on HRQoL in early relapsing-remitting multiple sclerosis. Mult Scler. 2007;13(6):783-791.

33. Bayoumi M, Al Harbi A, Al Suwaida A, Al Ghonaim M, Al Wakeel J, Mishkiry A. Predictors of quality of life in hemodialysis patients. Saudi $J$ Kidney Dis Transpl. 2013;24(2):254-259.

34. A. Abdelghany M, E. Elgohary E, Nienaa YA. Assessment of Health-Related Quality of Life in Patients Receiving Regular Hemodialysis. J Nephrol Ther. 2016;6(2) 